\title{
Thematic content analysis using ATLAS.ti software: Potentialities for researchs in health
}

\author{
Análise de conteúdo temática utilizando o software ATLAS.ti: potencilaidades para pesquisas em saúde
} Análisis temático de contenido mediante el software ATLAS.ti: potencialidades para las investigaciones en salud

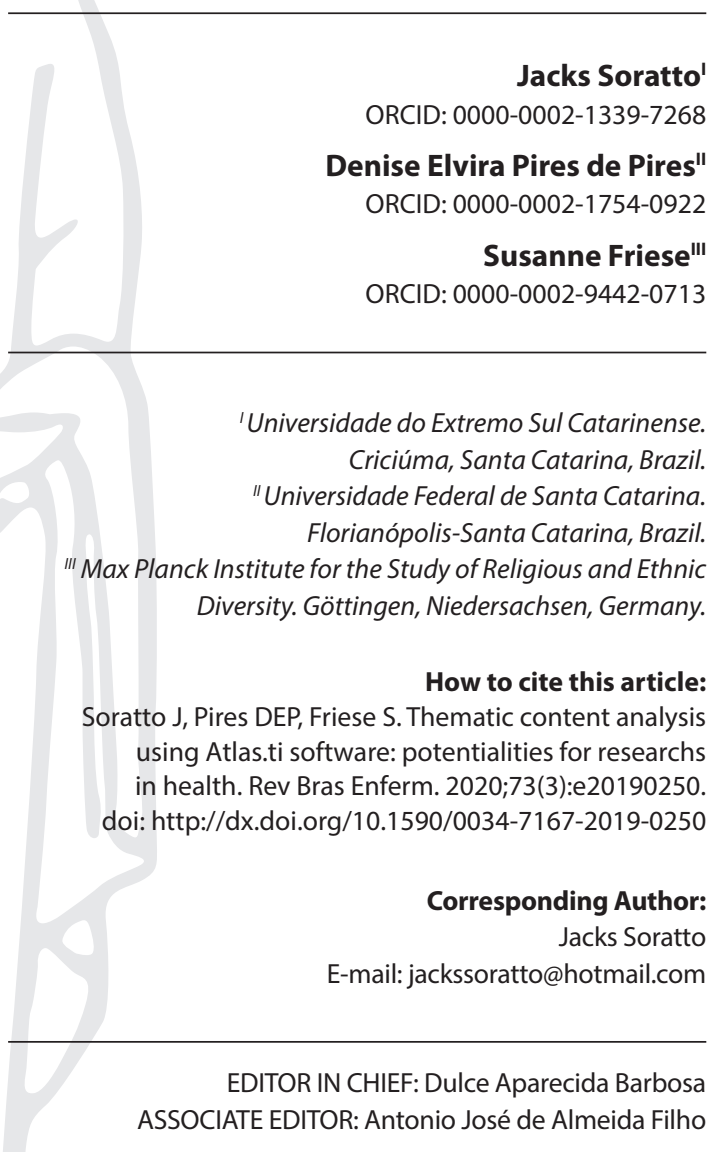

Submission: 01-07-2019

Approval: 12-10-2019

\section{ABSTRACT}

Objective: to describe the most important tools of ATLAS.ti Software and to associate them with the procedures of Thematic Content Analysis. Method: It is a theoretical reflection of the Content Analysis phases of Laurence Bardin, associating them with software tools Atlas. ti and showing its usefulness for data analysis in qualitative research. Results: historical contextualization and the available resources of Atlas.ti software with presentation of health research involving the phases of thematic content analysis. Final considerations: The Atlas.ti software assists in the accomplishment of the thematic content analysis being this promising association in health research.

Descriptors: Qualitative Research; Qualitative Analysis; Software; Information Management; Primary Health Care.

\section{RESUMO}

Objetivo: descrever as ferramentais mais importantes do software Atlas.ti associando-as aos procedimentos da análise temática de conteúdo temática. Método: trata-se de um reflexão teórica das fases da análise de conteúdo de Laurence Bardin, associado-a com as ferramentas do sotware Atlas.ti e monstrando sua utilidade para a análise de dados em pesquisa qualitativa. Resultados: contextualização histórica e dos recusos disponiveis do software Atlas.ti com apresentação de pesquisa em saúde envolvendo as fases da análise de conteudo temática. Considerações: o software Atlas.ti auxilia na efetivação da análise de conteúdo temática sendo esta associação promissora nas pesquisas em saúde. Descritores: Pesquisa Qualitativa; Análise qualitativa; Sofware; Gestão da Informação; Atenção Primária à Saúde.

\section{RESUMEN}

Objetivo: describir las herramientas más importantes del software ATLAS.ti y asociarlas con los procedimientos de Análisis de contenido temático. Método: es una reflexión teórica de las fases de análisis de contenido de Laurence Bardin, asociándolas con las herramientas de software Atlas.ti y mostrando su utilidad para el análisis de datos en la investigación cualitativa. Resultados: contextualización histórica y los recursos disponibles del software Atlas.ti con presentación de investigaciones en salud que involucran las fases del análisis de contenido temático. Consideraciones finales: el software Atlas.ti ayuda a la realización del análisis de contenido temático, siendo esta asociación prometedora en la investigación en salud. Descriptores: Investigación Cualitativa; Analisis Cualitativo; Software; Gestión de la Información Atención Primaria de Salud. 


\section{INTRODUCTION}

Currently, technological innovation affects all economic sectors, multiple areas of knowledge, including the research process itself. Beginning in the 1980s, computational resources have been increasingly used in research, and today numerous software programs are available for use in qualitative and quantitative research ${ }^{(1)}$. The acronym, CAQDAS (Computer Assisted Qualitative Data Analysis Software), refers to software created to assist with qualitative data analysis. The use of this type of technology in research is not without fault.

Several authors warn about the possibility of the researcher becoming too concerned with procedure, clipping specific words and phrases, which eventually result in data interpretation weaknesses that distance the findings from the context of the relationships and scenarios in which they occurred. Another criticism concerns the use of CAQDAS resources in order to imbue the research with scientific authenticity. However, the statements of qualitative theorists and researchers concerning the usefulness and risks of the software used in data analysis processes have diminished over the years with the evidence of its usefulness for analysis.

The software ATLAS.ti is an example of CAQDAS, which has been used by professionals and numerous researchers from different fields of knowledge, such as education, engineering, criminology, management, anthropology, as well as healthcare professionals such as nurses, physicians, and psychologists ${ }^{(2)}$. The ATLAS.ti can be used with different theoretical approaches and multiple data analysis processes. The use of Content Analysis formulated by Laurence Bardin is one of these possible approaches, and it is a useful resource for data analysis in qualitative research ${ }^{(2-3)}$.

\section{OBJECTIVE}

To describe the most important tools of ATLAS.ti Software and to associate them with the procedures of Content Analysis.

\section{METHODS}

This manuscript consists of a brief communication about theoretical and methodological reflection that presents the origin, features and tools contained in ATLAS.ti ${ }^{(2,4)}$ describes the components and processes involved in the Content Analysis phases of $\operatorname{Bardin}^{(3)}$, associating them with software tools and showing its usefulness for data analysis in qualitative research.

\section{ORIGIN, UTILITY AND TOOLS OF ATLAS.TI}

ATLAS.ti was designed by Thomas Muhr as part of a larger research project at the Technical University of Berlin from 1989 to 1992. The software was developed with the purpose of managing a large amount of research data that was collected in order to analyze the impact of the Chernobyl nuclear accident that occurred in 1986. In 1993, the first commercial version of the software was released ${ }^{(5)}$.
A demo version of ATLAS.ti can be downloaded for free and used for small projects. There is no expiration date. The limitations of the demo version are: you can work with 10 documents, create 100 quotations and 50 codes. If the project becomes larger, one can unlock the demo version by purchasing a license key. A range of licensing options are available starting from special low price options for students up to campus licenses and various lease options. ATLAS.ti is available for both Win and Mac computers.

Each two years have the international conferences were for users to exchange knowledge and to improve analytic skills. And also, each year, the International Institute for Qualitative Methodology (IIQM), University of Alberta, Canada, rewards the best master's thesis and doctoral dissertation based on qualitative research, which is sponsored by ATLAS.ti. Furthermore, the Qualitative Methods Master Class Webinar Series is organized and conducted as joint project between ATLAS.ti and IIQM.

The name for the software was inspired by the Greek God Atlas. According to Greek mythology, Atlas tried to conduct a raid to destroy Zeus. As he was unsuccessful, he received a punishment from Zeus for having confronted him, which was to carry the world on his shoulders. This myth represents the weight of daily difficulties and is related to excessive duties, obligations and accepted tasks ${ }^{(6)}$.

This myth typifies very well the central role of the software, that is to store and manage all information collected for a research project at one place. This means that the researcher will no longer have difficulties with manual duties of cutting out pieces of narrative, forming a collage of papers and posters, or developing spreadsheets and schemas to facilitate the process of systematization qualitative data. ATLAS.ti offers features to centralize all of the necessary information for organizing one's research, and has mechanisms to enable data analysis to be performed in the software itself, mediated by the researcher, who continues to play the central role in the analysis process being the critical thinker (2).

As shown in Figure 1, ATLAS.ti has all of the components that provide access to all commands, essential for all operations on its main screen. The main tools are accessible through at least two paths: vertical and horizontal.

The essential tools contained in ATLAS.ti that one needs to know about in order to understand its mode of operation are: project, documents, quotations, codes, comments, memos, groups, networks, reports and some project management features ${ }^{(4)}$.

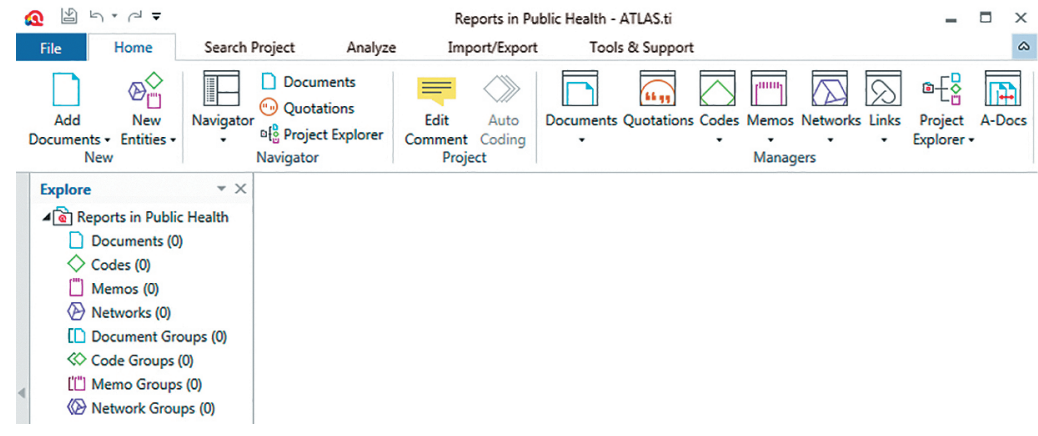

Source: Atlas.ti Software, 2020.

Figure 1 - Interface of the ATLAS.ti Software version 8.0 
Project: is the project file that contains all information relevant for a project. One starts with adding documents to a reserch, writing memos, creating quotations, writing comments, building a code structure and creating network views. All of these objects and linkages between objects, as well as all of your writings are contained with the project. What is not contained in the project, are your document source files as they would increase the size of the project. All source files like your transcripts, PDF files, images, audio or video data are copied to a document library and then linked to the project file. This increases efficiency of project and data management, and also allows researchers to work with a more sizeable data base.

Documents: the documents represent the empirical data that are added to a project as text, audio, video and image files. Each inserted document receives a consecutive number preceded by the letter D, e.g., D1, D2, D3, and so on.

Quotations: quotations are selected fragments of your data, e.g., an audio sample or a portion of a transcript from an interview, a segment of a picture or a document, or a portion of a video. They are selected by the investigator based on the problem to be analyzed and the research objective. Quotation can be coded but do not have to be coded. The default name for quotations for text documents are the first 30 characters of the selected text; for multimedia data it is the document name. This name can be renamed, e.g. to add short titles for video segments, or summaries for text data. It is possible to extend the quotation name to more than 30 characters. Each quotation can be commented and data can be linked to each other on the quotation level via so-called hyperlinks.

Codes: codes synthesize the meaning or the central information contained in a set of similar quotations. Code comments can be used to describe the meaning in more detail and also to summarize and interpret the data coded by each code.

Comments and Memos: The primary framework for operationalization are comments and memos. Comments can be written for each object (documents, quotations, codes, families, and network views). Memos are useful for a variety of purposes. They can be used as pure technical device to generate a list of codes, as reminders, as research diary, as a tool to exchange information in team work, or as building blocks for theory.

Code Groups: another devise are groups. As the name already indicate, these are group of objects. Document groups are generally used to group documents by sociodemographic characteristics, or other meta criteria like case information, dates, document types, location, etc. Document codes groups can also be created based on content that has been coded. They enable researchers to compare and contrast data based on any criteria of interest, like the attitudes of all females living in city $x$ and being above age 40 with males living in city $x$ being above 40 . Code groups are very useful for the process of retrieving and analyzing data. Their main purpose is to serve as filters, which also is an aid in building the coding frame.
Networks: another main feature is the network view function. It can be used to visualize any of the links that have been created during the process of coding, commenting and memo writing. It also incorporates some analytic functionality by being able to import neighboring or co-occurring objects. Network views can contain documents, codes, quotations, memos and codes groups. Code-Code links and quotation-quotation links can be named, and most objects can be linked to each other. For some objects virtual links can be displayed. This for instance applies to displaying codes by documents or document groups. The links are only virtual as codes are not directly linked to documents; they are only linked via the quotations they code. All of these features enable researchers to establish relationships between the elements mentioned based on the formulated objectives and the theoretical framework used in the research. The results presented in network views enrich inferential analysis and improve research findings. The figure 2 shows an example of network of the study Soratto et al. ${ }^{(1,7)}$.

Data Export: the available report options support the process of report writing by allowing to export data to text files or spreadsheets, and generating lists of documents, codes, quotations and memos and their associations with each other. Last but not least, ATLAS.ti offers tools that allow for easy project transfer between computers and between researchers. This feature can be used for team work and project backups.

Further Analysis Tools: once a project is set up and coded, further analysis tools help to query the data in all kind of ways. It is possible to cross-tabulate codes, or to cross-tabulate codes by documents or document groups; the query tool offers three set of operators (Boolean, semantic and proximity operators) that allow to ask code-based questions. Results can be turned into variables, or compared by groups of already existing variables. This allows researchers to go beyond the surface and to generate reliable and valid results.

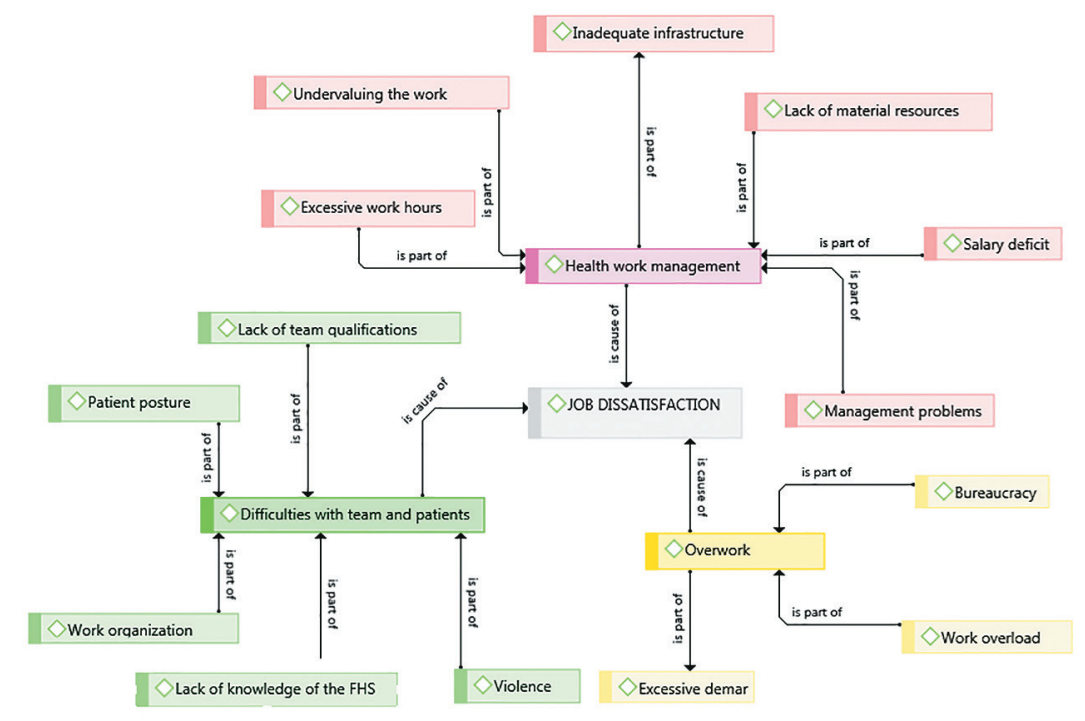

Note: FHS it means Family Health Strategy and belongs to Primary Health Care in Brazil.

Figure $\mathbf{2}$ - Relationships of the factors generating dissatisfaction of health care professionals working in primary health care 
Given the variety of tools available, reading this manuscript you may think that it is difficult and time consuming to learn and to understand the software. Based on our experience, we can only encourage researchers to learn the tools as the time invested to master them results in long-term benefits that greatly enhance the analytical research process.

\section{CONTENT ANALYSIS AND ATLAS.TI: A POSSIBLE AND PROMISING ASSOCIATION}

Content analysis is widely used in qualitative research and several techniques can be used, one of which is thematic or categorical analysis. The content analysis has three phases:"pre-analysis, material exploration and treatment of results, inference and interpretation"(3).

The first phase [pre-analysis] requires the choice of "documents to be analyzed for the formulation of hypotheses and objectives and the development of indicators to substantiate the final interpretation $^{\prime \prime 2}$. At this stage, a full reading of empirical data must be performed, whether it is data that have been transcribed or that are in form of documents, pictures, audio or video. All data collected for the study must be considered, for example, those obtained through interview, observation and documentary study, among others. At this stage, a project is created in ATLAS.ti and saved with the project name. All empirical data files, which the researcher considers useful in understanding the studied phenomenon are added to the project. A number is automatically assigned to each document, based on the order in which it is added to the project.

In the second phase [material exploration], the objective is to reach the central point of understanding of the text; it is a "long and tedious phase consisting essentially of coding operations, decomposition or numbering"(2). At this stage, quotations are created based on the research objectives and the theoretical framework, and a code is assigned to each quotation. The code label is a word or phrase that synthesizes the main idea contained in a set of similar quotations. Bardin ${ }^{(2)}$ describes the encoding process as the"[...] transformation of raw text data, clipping, aggregation and enumeration, allowing them to achieve a representation of the content or its expression". Helpful at this stage are the visibility of code frequency in the ATLAS.ti Code Manager, the ease of data retrieval to check and validate code segments and the code families to help building the final coding structure.

In the third phase [interpretation], the "raw data are processed in order to be meaningful and valid", enabling the researcher to "establish the results of tables, diagrams, figures"(2). In this phase, the coded data is queried according to the research objectives and the theoretical framework. Depending on the type of questions and the type of data at hand, all or only a few of the above mentioned analysis tools can be used. The code-occurrence and the codesdocuments matrix both result in tables that quantify the findings, however, offering the possibility to view the qualitative data behind the numbers as well. At this stage, memo writing becomes important again as in writing a lot of the transformation into meaningful results occur. These memos along with coded data segments and results of queries can later be used as parts of the research report. Network views at this stage are used to visualize the conceptual links that have become apparent during the analysis process.

In Chart 1 the application of a example of the various phases of content analysis within ATLAS.ti are synthesized.

Chart 1 - Applying the various stages of content analysis in ATLAS.ti

\begin{tabular}{|c|l|}
\hline $\begin{array}{c}\text { Phases of } \\
\text { thematic } \\
\text { content } \\
\text { analysis }\end{array}$ & \multicolumn{1}{|c|}{ Steps in ATLAS.ti } \\
\hline $\begin{array}{c}\text { First phase: } \\
\text { Pre-analysis. }\end{array}$ & $\begin{array}{l}\text { Creating the project. } \\
\text { Adding documents. } \\
\text { Grouping documents into document groups. } \\
\text { Writing first memos on the overall project aim } \\
\text { including research questions. }\end{array}$ \\
\hline $\begin{array}{c}\text { Second phase: } \\
\text { exploration. }\end{array}$ & $\begin{array}{l}\text { Reading the data, selecting data segments and } \\
\text { creating quotations. } \\
\text { Creating and applying codes. } \\
\text { Writing memos and comments. } \\
\text { Grouping codes and memos }\end{array}$ \\
\hline $\begin{array}{c}\text { Third phase: } \\
\text { Interpretation. }\end{array}$ & $\begin{array}{l}\text { Exploring the coded data using various analysis tools. } \\
\text { conceptual level. } \\
\text { Continuing memo writing. } \\
\text { Generating network views. } \\
\text { Extracting reports. }\end{array}$ \\
\hline
\end{tabular}

\section{FINAL CONSIDERATIONS}

The software ATLAS.ti is promising strategy for conducting content analysis and the software enables researchers to store all relevant information in one place, providing greater data management security and eliminating manual tasks. This allows researchers to spend more time with analyzing data, plus the available software tools offer more sophisticated ways of exploring the data. However, the software does not perform automated data analysis. All the relationships that are created during the analysis process are based upon the investigator's decision. This manifests the important role of the researcher in remaining a critical analyst during all stages of the research process.

\section{FUNDING}

Conselho Nacional de Desenvolvimento Científico e Tecnológico (CNPq), Brazil, with process number 233152/2014-8.

Coordenação de Aperfeiçoamento de Pessoal de Nível Superior (CAPES), Brasil, with financial support for study to the first author this paper between the years 2012 to 2015.

\section{REFERENCES}

1. Friese S, Soratto J, Pires D. Carrying out a computer-aided thematic content analysis with ATLAS.ti. MMG Working Paper[Internet]. 2018 [cited 2018 Feb 25]. Available from: http://www.mmg.mpg.de/fileadmin/user_upload/documents/wp/WP_18-02_Friese-Soratto-Pires_ AtlasTI.pdf 
2. Friese S. Qualitative Data Analysis with ATLAS.ti. 3. ed. London: Sage, 2019.

3. Bardin L. Análise de conteúdo. São Paulo: Edições 70, 2011.

4. Atlas.ti. ATLAS.ti Scientific Software Development GmbH. Qualitative Data Analysis. Version 8.0. Berlin, 2018.

5. Legewie H. ATLAS.ti. How It All Began. A Grandfather's Perspective. In: ATLAS.ti User Conference 2013: Fostering Dialog on Qualitative Methods [Internet]. 2013 [cited 102018 Feb 25]. Available from: http: https://atlasti.com/2013/02/22/ announcement-atlas-ti-user-conference-fostering-dialog-qualitative-methods-sept-2013-berlin/

6. Rand A. A revolta de Atlas. Trad. Britto, Paulo Henriques. Ed. Arqueiro, v. 1, 2010.

7. Soratto J, Pires DEP, Trindade LL, Oliveira JSA, Forte ECN, Melo TP. Job dissatisfaction among health professionals working in the family health strategy. Texto Contexto Enferm. 2017;26:1-11. doi: 10.1590/0104-07072017002500016. 